\title{
From epithelial cell cultures to quality of life of the surgeon
}

This issue of the journal shows the variety of research in our field.

From very basic research evaluating the role of epithelial cells in upper airway inflammation to quality of life research not only of our patients but this time also of the rhinologists themselves. Epithelial cells are among the first responders to invading allergens and microbes, and mount an immediate innate immune response ${ }^{(1-3)}$. Defects in the innate response and the barrier function of the epithelium seem to play an important role in diseases like allergic rhinitis (AR) and chronic rhinosinusitis (CRS). Shiozawa and colleagues now show that in AR and CRSwNPs a significant up-regulation in the release of IL-6, IL-33, and thymic stromal lymphopoietin (TSLP) occurs compared to normal controls and that stimulation with II-17A, which plays a significant role in both the recruitment of eosinophils and the remodeling of the nasal polyps of CRS, further enhances this production ${ }^{(4)}$.

A very controversial issue is discussed in the review of Eccles and Wilkinson ${ }^{(5)}$. When you ask the public what causes a common cold, a very popular answer is cooling of the body, standing at a drafty place, etc. Although there is a clear correlation between average air temperature and upper respiratory tract infection (URTI), in this review paper Eccles and Wilkinson find very little evidence that chilling of the nasal airway, the mouth, the body surface and even hypothermia causes URTI. Unfortunately, this also means that preventing getting cold will not prevent getting a cold. Another ongoing debate is the role of post nasal drip in the evaluation of cough ${ }^{(6-9)}$. Although almost 10 years ago $\mathrm{O}^{\prime} \mathrm{Hara}$ and Jones already showed that only a small proportion of patients with purulent rhinosinusitis without coexisting chest disease complain of cough and thus that it is unlikely to be a common cause for chronic cough, still, we are consistently asked to evaluate post nasal drip as an important factor in unexplained cough. In this issue, Rimmer et al. show in a very elegant way that the insertion of two different viscosities of artificial mucus to produce PND did not induce cough in healthy controls nor in patients with allergic rhinitis (10).

We are in need of easy tools to objectively measure nasal obstruction. Rhinomanometry and acoustic rhinometry are, although very well evaluated, to cumbersome for daily use ${ }^{(11)}$. A lot of research has been performed in the last years to determine the effectiveness of peak nasal inspiratory flow (PNIF). Normal values in children and adults have been published ${ }^{12,}$ 13) and it has been shown that it is possible to reliably measure unilateral PNIF ${ }^{(14,15)}$. It was recently shown that PNIF is a reliable method to measure treatment effect after septoplasty and inferior turbinate coblation ${ }^{(16)}$, valve deficiency ${ }^{(17)}$ and allergic rhinitis in children ${ }^{(18)}$. Now in this issue, Martins de Oliveira et al. show that there is a very weak correlation between PNIF and symptoms score emphasizing the need for objective measurements of nasal obstruction when evaluating treatment effects (19).

Bleeding during surgery is not only a nuisance but can be really dangerous. In recent years, a lot of research has been done to evaluate which factors can reduce intraoperative bloodloss. Certain procedures, such as the reverse Trendelenburg position, the use of high doses of epinephrine, the infiltration of phenylephrine and lidocaine into the pterygopalatine fossa, the preoperative use of prednisone, and the control of the heart rate (with dexmedetomidine or remifentanil) and the use of intra-operative local and systemic tranexamic acid and the use of TIVA, appear to reduce the intraoperative blood loss and/or improve the visualisation of the surgical field (20-22). In this issue, Cardesín et al. show that the use of clonidine- based controlled hypotensive anaesthesia achieves lower surgical field bleeding during FESS than remifentanil ${ }^{(23)}$. Because there seems to be a continuous debate, it might be worthwhile to write a consensus document involving anaesthesiologists and rhinologist to describe optimal anaesthesia for sinus surgery.

Finally endoscopic sinus surgery has significantly improved the quality of life of our patients ${ }^{(24-27)}$. However, our own quality of life does not always improve by doing this kind of surgery. Amin et al. evaluated the prevalence and severity of musculoskeletal symptoms attributed to the use of endoscope or body posture during endoscopic sinus surgery: more than half of the respondents complained about pain and stiffness in back, neck, shoulders and fingers. This emphasizes the need to increase awareness among surgeons, familiarize ourselves with good operating posture habits and new ergonomic instruments and to give attention to optimal posture habits to residents in training ${ }^{(28)}$. I wish you a lot of reading pleasure. 


\section{References}

1. Choi YS, Bae CH, Song SY, Kim YD. The effect of Epigallocatechin-3-gallate in allergic airway inflammation. Rhinology. 2014; 52: 406412.

2. Golebski K, Roschmann KI, Toppila-Salmi S, Hammad H, Lambrecht BN, Renkonen R, et al. The multi-faceted role of allergen exposure to the local airway mucosa. Allergy. 2013; 68: 152-60.

3. Toppila-Salmi S, van Drunen CM, Fokkens WJ, Golebski K, Mattila P, Joenvaara S, et al. Molecular mechanisms of nasal epithelium in rhinitis and rhinosinusitis. Curr Allergy Asthma Rep. 2015; 15: 495.

4. Shiozawa A, Miwa M, Ono N, Homma H, Hirotsu M, Ikeda K. Comparative analysis of cytokine release from epithelial cell cultures of the upper airway. Rhinology. 2015; 53 135-141.

5. Eccles R, Wilkinson JE. Exposure to cold and acute upper respiratory tract infection. Rhinology. 2015; 53: 99-106.

6. Kemp A. Does post-nasal drip cause cough in childhood? Paediatr Respir Rev. 2006; 7: 31-35.

7. O'Hara J, Jones NS. "Post-nasal drip syndrome": most patients with purulent nasa secretions do not complain of chronic cough. Rhinology. 2006; 44: 270-273.

8. Sanu A, Eccles R. Postnasal drip syndrome. Two hundred years of controversy between UK and USA. Rhinology. 2008; 46: 86-91.

9. Loehrl TA, Toohill RJ. Postnasal drip syndrome. Rhinology. 2008; 46: 348; author reply

10. Rimmer J, Hellgren J, Harvey RJ. Simulated postnasal mucus fails to reproduce the symptoms of postnasal drip in rhinitics but only in healthy subjects. Rhinology. 2015; 53: 129-134.

11. Chaves C, de Andrade CR, Ibiapina C.
Objective measures for functional diagnostic of the upper airways: practical aspects. Rhinology. 2014; 52: 99-103.

12. Ottaviano G, Scadding GK, Coles S, Lund VJ. Peak nasal inspiratory flow; normal range in adult population. Rhinology. 2006; 44: 32-35.

13. van Spronsen E, Ebbens FA, Fokkens WJ Normal peak nasal inspiratory flow rate values in healthy children aged 6 to 11 years in the Netherlands. Rhinology. 2012; 50: 22-25.

14. Ottaviano G, Lund VJ, Nardello E, Scarpa B, Frasson G, Staffieri A, et al. Comparison between unilateral PNIF and rhinomanometry in healthy and obstructed noses. Rhinology. 2014; 52: 25-30.

15. Ottaviano G, Scadding GK, Scarpa B, Accord D, Staffieri A, Lund VJ. Unilateral peak nasal inspiratory flow, normal values in adult population. Rhinology. 2012; 50: 386-392.

16. Balikci HH, Gurdal MM. Use of peak nasal inspiratory flowmetry and nasal decongestant to evaluate outcome of septoplasty with radiofrequency coblation of the inferior turbinate. Rhinology. 2014; 52: 112-115.

17. Hellings PW, Nolst Trenite GJ. Improvement of nasal breathing and patient satisfaction by the endonasal dilator Airmax. Rhinology 2014; 52: 31-34.

18. de Souza Campos Fernandes S, Ribeiro de Andrade C, da Cunha Ibiapina C. Application of Peak Nasal Inspiratory Flow reference values in the treatment of allergic rhinitis. Rhinology. 2014; 52: 133-136.

19. Martins de Oliveira GM, Rizzo JA, Moreira Camargos PA, Cavalcanti Sarinho ES. Are measurements of peak nasal flow useful for evaluating nasal obstruction in patients with allergic rhinitis? Rhinology. 2015; 53: 160-166.

20. Pundir V, Pundir J, Georgalas C, Fokkens WJ. Role of tranexamic acid in endoscopic sinus surgery - a systematic review and metaanalysis. Rhinology. 2013; 51: 291-297.

21. Rodriguez Valiente $A$, Roldan Fidalgo A, Laguna Ortega D. Bleeding control in endoscopic sinus surgery: a systematic review of the literature. Rhinology. 2013; 51: 298-305.

22. Marzban S, Haddadi S, Mahmoudi Nia H, Heidarzadeh A, Nemati S, Naderi Nabi B. Comparison of surgical conditions during propofol or isoflurane anesthesia for endoscopic sinus surgery. Anesth Pain Med. 2013; 3: 234-238.

23. Cardesin A, Pontes C, Rosell R, Escamilla Y, Marco J, Escobar MJ, Bernal-Sprekelsen M. A randomised double blind clinical trial to compare surgical field bleeding during endoscopic sinus surgery with clonidinebased or remifentanil-based hypotensive anaesthesia. Rhinology. 2015; 53: 107-115.

24. Taylor RJ, Miller JD, Rose AS, Drake AF, Zdanski CJ, Senior BA, et al. Comprehensive quality of life outcomes for pediatric patients undergoing endoscopic sinus surgery. Rhinology. 2014; 52: 327-333.

25. Cornet ME, Georgalas C, Reinartz SM Fokkens WJ. Long-term results of functional endoscopic sinus surgery in children with chronic rhinosinusitis with nasal polyps. Rhinology. 2013; 51: 328-334.

26. Hopkins C, Slack R, Lund V, Brown P, Copley $\mathrm{L}$, Browne J. Long-term outcomes from the English national comparative audit of surgery for nasal polyposis and chronic rhinosinusitis. Laryngoscope. 2009; 119: 24592465.

27. Soler ZM, Smith TL. Quality of life outcomes after functional endoscopic sinus surgery. Otolaryngol Clin North Am. 2010; 43: 605612.

28. Amin $M$, Rimmer J, Swift $A$, White $P$, Lund $V J$. FESS, fingers and other things - you are not alone! Rhinology. 2015; 53: 116-121.
Wytske J. Fokkens, Editor-in Chief Amsterdam, the Netherlands

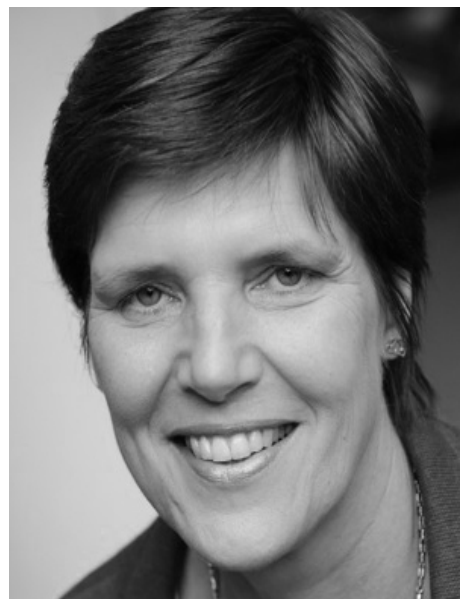

